\title{
Increasing the Wear Resistance of Ultra-High Molecular Weight Polyethylene by Adding Solid Lubricating Fillers
}

\author{
S. V. Panin ${ }^{1,2, a)}$, L. A. Kornienko ${ }^{1}$, T. Nguen $\operatorname{Suan}^{2}$, \\ M. A. Poltaranin ${ }^{1}$, and L. R. Ivanova ${ }^{1}$ \\ ${ }^{1}$ Institute of Strength Physics and Materials Science SB RAS, Tomsk, 634055, Russia \\ ${ }^{2}$ National Research Tomsk Polytechnic University, Tomsk, 634050, Russia \\ a) Corresponding author: svp@ispms.tsc.ru
}

\begin{abstract}
In order to compare effectiveness of adding solid lubricating fillers for polymeric composites based on ultrahigh molecular weight polyethylene (UHMWPE) with graphite, molybdenum disulfide and polytetrafluoroethylene, their tribotechnical characteristics under dry friction, boundary lubrication and abrasive wearing were investigated. The optimal weight fractions of fillers in terms of improving wear resistance have been determined. The supramolecular structure and topography of wear track surfaces of UHMWPE-based composites with different content of fillers have been studied.
\end{abstract}

Keywords: ultra-high molecular weight polyethylene, filler, graphite, molybdenum disulfide, polytetrafluoroethylene, supramolecular structure, wear resistance

\section{INTRODUCTION}

Ultra-high molecular weight polyethylene (UHMWPE) possesses quite appropriate for polymers strength characteristics, while the low friction coefficient, high wear- and chemical resistance in corrosive environments, high impact toughness and low temperature of embrittlement ensure its wide application in various fields of engineering and operating conditions. The use of UHMWPE-based composite materials enables the many-fold improvement of the wear resistance of metal-polymeric tribological couplings. Currently, UHMWPE-based microand nanocomposites are being intensively developed. The certain types and sizes of fillers are defined by the range of application and environment where the composites are to be used (vacuum, reactive and inert environment, cryogenic or elevated temperatures) [1-4].

Solid lubricating fillers (graphite, molybdenum disulfide, polytetrafluoroethylene/teflon, etc.) are widely used as lubricants (oil additive) and antifriction coatings in the wide range of temperatures. To choose a lubrication method one should take into account the design and operating conditions of a friction pair. In this paper the solid lubricants are added as the fillers into UHMWPE as it can operate effectively even at very low temperatures (e.g., at cryogenic ones) when liquid or pasty lubricant cannot withstand the extreme operating conditions.

The objective of the study was to perform a comparative analysis of the mechanical properties and the tribotechnical characteristics of the UHMWPE- based composites with solid lubricating fillers $\mathrm{MoS}_{2}$, graphite and teflon under dry friction, boundary lubrication and abrasive wear.

\section{EXPERIMENTAL}

The specimens were sintered using GUR-2122 UHMWPE-powder (Ticona, Germany) with molecular weight of $4.0 \mathrm{mln}$ and particle size of 5-15 $\mu \mathrm{m}$. Colloidal graphite C-1 $(\varnothing 1-4 \mu \mathrm{m})$, molybdenum disulfide SPM-1 $(\varnothing 1-7 \mu \mathrm{m})$ and polytetrafluoroethylene F-4PN $\mathrm{PN}_{20}(\varnothing 14 \mu \mathrm{m})$ were employed as solid lubricants. Specimens were hot-compacted

International Conference on Physical Mesomechanics of Multilevel Systems 2014

AIP Conf. Proc. 1623, 471-474 (2014); doi: 10.1063/1.4898984

(C) 2014 AIP Publishing LLC 978-0-7354-1260-6/ $\$ 30.00$ 
at the pressure of $10 \mathrm{MPa}$ and the temperature of $200^{\circ} \mathrm{C}$ with the subsequent cooling rate of $5^{\circ} \mathrm{C} / \mathrm{min}$. Polymer blends (mixtures) of UHMWPE-powder with fillers $\left(\mathrm{C}, \mathrm{MoS}_{2}\right.$, PTFE) were prepared in a MR/0.5*4 planetary ball mill with the preliminary dispersing of the components in an ultrasonic bath.

The wear resistance of materials under dry friction was estimated by "block-on-ring" scheme with the use of SMT-1 wear testing machine under the load of $68.8 \mathrm{~N}$ applied onto a pair of specimens, the roller revolution frequency of $100 \mathrm{rpm}$ and the sliding velocity of $0.32 \mathrm{~m} / \mathrm{s}$ (in accordance with ASTM G99). The dimensions of the specimens were $7 \times 7 \times 10 \mathrm{~mm}(H \times W \times L)$. Diameter of the roller made of bearing steel was $62 \mathrm{~mm}$. Friction/wear surfaces of the specimens were examined by Zygo New View 6200 optical profilometer. The area of wear track was determined with the use of the Rhino Ceros 3.0 software by manual tracing of the wear track and subsequent automatic calculation of its area.

Abrasion tests were performed with the use of an abrader (MI-2 testing machine for rubber wear). Wear intensity was measured at the normal load of $0.15 \mathrm{MPa}$ applied to a pair of specimens and the sliding velocity of a disk of $17.0 \mathrm{~m} / \mathrm{min}$ in relation to specimens. Fixed abrasive particles P 240 (sand abrasive paper) with the grain size of $58.5 \mu \mathrm{m}$ (GOST 426) were used. Volumetric abrasive wear of the specimens was determined by their weighing and further calculating of the mass loss in every 5 minutes. The testing method meets the requirements of ASTM G99 and DIN 50324.

Structural studies were carried out using a LEO EVO 50 scanning electron microscope at the accelerating voltage of $20 \mathrm{kV}$ on the cleavage surfaces of notched specimens that were mechanically fractured after soaking in liquid nitrogen. The mechanical characteristics were determined by tensile tests of dumbbell test specimen (with the number of specimens of each type not less than 5) performed using Instron 5582 electromechanical testing machine.

TABLE 1. Mechanical properties and friction coefficient of UHMWPE-C composites

\begin{tabular}{|c|c|c|c|c|c|c|}
\hline $\begin{array}{l}\text { Filler Content } \\
\text { (C), wt.\% }\end{array}$ & $\begin{array}{l}\text { Density, } \rho, \\
\quad \mathrm{g}^{\mathrm{cm}} \mathbf{c m}^{3}\end{array}$ & $\begin{array}{c}\text { Shore } \\
\text { Hardness } D\end{array}$ & $\begin{array}{c}\text { Yield Point } \\
\sigma_{0.2}, \mathrm{MPa}\end{array}$ & $\begin{array}{c}\text { Ultimate } \\
\text { Strength, } \sigma_{\mathrm{u}} \\
\mathrm{MPa}\end{array}$ & $\begin{array}{c}\text { Elongation at } \\
\text { Failure } \varepsilon, \%\end{array}$ & $\begin{array}{c}\text { Friction } \\
\text { Coefficient } f\end{array}$ \\
\hline 0 & 0.936 & $56.7 \pm 0.6$ & $19.2 \pm 0.9$ & $34.3 \pm 1.7$ & $470 \pm 23.6$ & 0.12 \\
\hline 3 & 0.953 & $57.5 \pm 0.5$ & $19.5 \pm 1.0$ & $30.3 \pm 1.5$ & $471 \pm 23.8$ & 0.10 \\
\hline 5 & 0.967 & $57.5 \pm 0.4$ & $19.6 \pm 1.2$ & $29.7 \pm 1.5$ & $513 \pm 25.1$ & 0.11 \\
\hline 10 & 0.989 & $57.6 \pm 0.6$ & $20.1 \pm 1.3$ & $28.5 \pm 1.8$ & $538 \pm 25.3$ & 0.12 \\
\hline \multicolumn{7}{|c|}{ TABLE 2. Mechanical properties and friction coefficient of UHMWPE-MoS ${ }_{2}$ composites } \\
\hline $\begin{array}{l}\text { Filler Content } \\
\left(\mathrm{MoS}_{2}\right) \text {, wt.\% }\end{array}$ & $\begin{array}{l}\text { Density, } \rho, \\
{\mathrm{g} / \mathrm{cm}^{3}}^{3}\end{array}$ & $\begin{array}{c}\text { Shore } \\
\text { Hardness } D\end{array}$ & $\begin{array}{c}\text { Yield Point } \\
\sigma_{0.2}, \mathrm{MPa}\end{array}$ & $\begin{array}{c}\text { Ultimate } \\
\text { Strength, } \sigma_{\mathrm{u}}, \\
\mathrm{MPa}\end{array}$ & $\begin{array}{l}\text { Elongation at } \\
\text { Failure } \varepsilon, \%\end{array}$ & $\begin{array}{c}\text { Friction } \\
\text { Coefficient } f\end{array}$ \\
\hline 0 & 0.936 & $56.7 \pm 0.6$ & $19.2 \pm 0.9$ & $34.3 \pm 1.7$ & $470 \pm 23.6$ & 0.120 \\
\hline 3 & 0.954 & $56.2 \pm 0.6$ & $18.4 \pm 0.8$ & $26.2 \pm 1.9$ & $494 \pm 24.6$ & 0.095 \\
\hline 5 & 0.975 & $56.9 \pm 0.5$ & $18.6 \pm 0.7$ & $26.9 \pm 1.6$ & $515 \pm 25.3$ & 0.100 \\
\hline 10 & 1.010 & $56.9 \pm 0.5$ & $18.7 \pm 0.9$ & $26.7 \pm 1.9$ & $535 \pm 24.1$ & 0.110 \\
\hline \multicolumn{7}{|c|}{ TABLE 3. Mechanical properties and friction coefficient of UHMWPE- PTFE composites } \\
\hline $\begin{array}{l}\text { Filler Content } \\
\text { (PTFE), wt.\% }\end{array}$ & $\begin{array}{l}\text { Density, } \rho, \\
\text { g/cm }\end{array}$ & $\begin{array}{c}\text { Shore } \\
\text { Hardness } D\end{array}$ & $\begin{array}{c}\text { Ultimate } \\
\text { Strength, } \sigma_{u}, \\
\mathrm{MPa}\end{array}$ & $\begin{array}{l}\text { Elongation at } \\
\text { Failure } \varepsilon, \%\end{array}$ & $\begin{array}{c}\text { Crystall. } \\
\chi, \%\end{array}$ & $\begin{array}{c}\text { Friction } \\
\text { Coefficient } f\end{array}$ \\
\hline 0 & 0.926 & $59.5 \pm 0.6$ & $32.3 \pm 0.9$ & $485 \pm 23.6$ & 44.8 & 0.120 \\
\hline 5 & 0.970 & $59.8 \pm 0.5$ & $29.2 \pm 1.0$ & $465 \pm 23.6$ & 39.5 & 0.067 \\
\hline 10 & 1.000 & $59.6 \pm 0.6$ & $27.0 \pm 1.2$ & $428 \pm 25.1$ & 35.8 & 0.067 \\
\hline 20 & 1.060 & $59.7 \pm 0.6$ & $24.7 \pm 1.3$ & $406 \pm 24.3$ & 35.0 & 0.068 \\
\hline 40 & 1.220 & $59.8 \pm 0.6$ & $20.2 \pm 1.0$ & $217 \pm 23.2$ & 26.0 & 0.075 \\
\hline
\end{tabular}




\section{RESULTS AND DISCUSSION}

Tables 1 to 3 show the tribomechanical characteristics of UHMWPE and the following composites: UHMWPE + $n$ wt. $\% \mathrm{C}$, UHMWPE $+n$ wt. $\% \mathrm{MoS}_{2}$ and UHMWPE $+n$ wt.\% PTFE. One can see from the tables that the mechanical properties after adding the fillers (yield point, elongation) are negligibly affected, while the friction coefficient of all investigated compositions decreases. The tribotechnical characteristics of these composites depend strongly on the filler weight fraction and the type of wear testing (dry friction, boundary lubrication, abrasive wear).

Dry sliding friction. The diagrams illustrating the wear intensities at steady-state wearing stage $\left(I, \mathrm{~mm}^{2} / \mathrm{min}\right)$ of the above described composites are presented in Fig. 1. According to Fig. 1(b), the lowest wear rate is specific for the following composites: UHMWPE + (3-5) wt.\% C and UHMWPE $+10 \mathrm{wt} . \% \mathrm{MoS}_{2}$ (the wear rate decreased almost 2-fold as compared with the pure UHMWPE). The roughness of the wear track surface in the composites fully correlates with the wear intensity.

For UHMWPE-PTFE composites the optimal content of the filler (PTFE) also amounted $10 \mathrm{wt} . \%$. Thus, the optimal weight fraction of the solid fillers to provide a two-fold increase of wear resistance under dry sliding friction have been determined. Further increasing of the content of these fillers is not effective since the wear resistance of UHMWPE-based composites under dry sliding friction is not improved.

In order to clarify the relationship between the wear pattern at dry sliding friction, the formed structure and the type and weight fraction of the fillers of the UHMWPE-based composites their wear track surface topography (at the steady-state wearing stage) and supramolecular structure were investigated. It was shown that filling of UHMWPE by particles of carbon, molybdenum disulfide and polytetrafluoroethylene gives rise to a gradual change in the pattern of supramolecular structure. If this takes place the formation of a spherulitic structure is suppressed, and the supramolecular structure of UHMWPE-based composites becomes less homogeneous due to prevented growth of spherulites by the filler particles during the crystallization. The difference in the development of the tribotechnical characteristics of UHMWPE is related to their lubricity (adhesion to the metal of a counterbody) defined by the structure features of the lattices of graphite, molybdenum disulfide and polytetrafluoroethylene [3].

Friction under boundary lubrication. The results of the wear tests of all above described composites conducted in a lubricating medium (distilled water) indicate that in the distilled water the fillers under study also act as solid lubricants. Firstly, in the presence of boundary lubrication the wear rate decreases both in pure (unfilled) UHMWPE and in the composites UHMWPE $+n$ wt. $\% \mathrm{MoS}_{2}$, UHMWPE $+\underline{\mathrm{n}} \mathrm{wt} . \% \mathrm{C}$ and UHMWPE $+n$ wt. $\%$ PTFE. Secondly, the wear rate of the above mentioned composites in the distilled water is lower than that of the pure UHMWPE in the same lubricating medium. The roughness of wear track surfaces ( $\mathrm{Ra}$ ) of the composites in the lubricating medium is lower than that of pure UHMWPE. These results evidence for the fact that the fillers (molybdenum disulfide, graphite and polytetrafluoroethylene) serve as solid lubricants during the wear of UHMWPE-based composites under dry sliding friction (the liquid water boundary lubrication is similar to solid lubricants that make up a part of polymer composites).

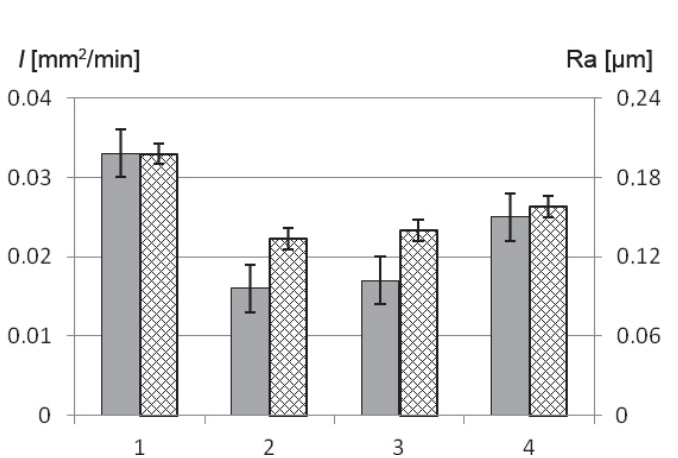

(a)

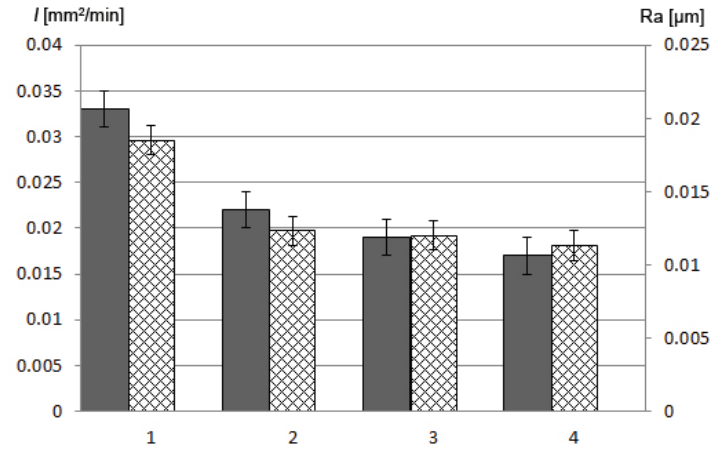

(b)

FIGURE 1. Wear intensity $I$ and roughness of wear track surface Ra of UHMWPE and composites on its basis. Steady-state stage for conditions of dry sliding friction: (a) pure UHMWPE (1), UHMWPE + $3 \mathrm{wt} . \%$ of C (2),

UHMWPE + 5 wt. $\%$ of C (3), UHMWPE + 10 wt. $\%$ of C (4); (b) pure UHMWPE (1),

UHMWPE +3 wt. $\%$ of $\mathrm{MoS}_{2}$ (2), UHMWPE +5 wt. $\%$ of $\mathrm{MoS}_{2}$ (3), UHMWPE $+10 \mathrm{wt} . \%$ of $\mathrm{MoS}_{2}$ (4) 
Abrasive wear. The influence of the fillers $\left(\mathrm{C}, \mathrm{MoS}_{2}\right.$ and PTFE) on the abrasive wear resistance of UHMWPEbased microcomposites was also analyzed. It was shown that the abrasion resistance of UHMWPE is increased with its filling by molybdenum disulfide and graphite from 1.3 to 1.5 times. Moreover, the molybdenum disulfide-filled composites exhibit somewhat higher wear resistance as compared with composites of UHMWPE $+n$ wt. $\%$ C. In addition, the wear resistance weakly depends on the content of graphite in the blends, while molybdenum disulfide is more effective when its weight fraction is 3 to $5 \mathrm{wt} . \%$ (even under abrasive wear with the use of abrasive grade of $\mathrm{P}$ 240). These results evidence the fact that the molybdenum disulfide and graphite facilitate the sliding of abrasive particles along the specimen surface in the case of dry sliding friction, but they cannot "protect" the matrix from cutting, since their sizes incommensurability smaller in contrast with abrasive grains $(1-4 \mu \mathrm{m}$ vs. $58.6 \mu \mathrm{m}$, respectively). The abrasive wear for UHMWPE filled with PTFE is similar to that of pure UHMWPE. This is the reason why the roughness of wear track surfaces $(\mathrm{Ra})$ depends on the filler size and its weight fraction. During the testing of these composites, the fixed abrasive particles cut the matrix, and soft polytetrafluoroethylene cannot "protect" it (the grooves in the wear surface of the compositions are comparable with those in the pure UHMWPE). Apparently, the soft polytetrafluoroethylene only facilitates the sliding of abrasive paper along the surface of specimens under wearing [5].

\section{CONCLUSIONS}

The following weight fraction of fillers: graphite micropowders (3 wt.\%), molybdenum disulfide (10 wt.\%) and PTFE (10 wt.\%) provides nearly two-fold increase of wear resistance under dry sliding friction. This effect is accompanied by almost 1.5 -fold decrease of the friction coefficient.

Molybdenum disulfide, graphite and polytetrafluoroethylene serve as a solid lubricant under the wearing of UHMWPE-based composites under boundary lubrication as well. The role of $\mathrm{C}$ and $\mathrm{MoS}_{2}$ as solid lubricant under the abrasive wear in improving the wear resistance of UHMWPE-based polymer composites is partially hindered by the disproportionate size of fillers and fixed abrasive particles. In doing so, the molybdenum disulfide is a more efficient filler in terms of improving the abrasive wear resistance.

The soft polytetrafluoroethylene particles admixed to HMWPE are unable to "protect" the matrix against the fixed abrasive particles. This is the reason why the UHMWPE-PTFE composites are not resistant against abrasive wearing. However, UHMWPE-PTFE composites (with up to $10 \mathrm{wt} . \%$ of filler) can be effectively used for friction joints (in particular, in medicine) for effective operation in the case of lubricant medium absence.

Filling of UHMWPE by the solid lubricating $\mathrm{C}$ and $\mathrm{MoS}_{2}$ microparticles is effective means for increasing the wear resistance under all three studied types of the wear. Therefore, UHMWPE-based composites (UHMWPE + $10 \mathrm{wt} . \% \mathrm{MoS}_{2}$ and UHMWPE $+3 \mathrm{wt} . \% \mathrm{C}$ ) can be used for the manufacturing of friction joints to operate in the absence of lubrication under extreme operating conditions.

\section{REFERENCES}

1. H. L. Stein, "Ultra High Molecular Weight Polyethylene (UHMWPE)", Engineered Materials Handbook, Vol. 2: Engineering Plastics, 1999.

2. $\quad$ P. R. Buseck, V. V. Kovalevski, and J. M. Cowley, Carbon 39(2), 243 (2001).

3. N. K. Myshkin, M. I. Petrokovets, and A. V. Kovalev, Tribol. Int. 38, 910 (2005).

4. S. V. Panin, L. A. Kornienko, V. P. Sergeev, N. Sonjaitham, and M. V. Tchaikina, "Wear-Resistant UltrahighMolecular-Weight Polyethylene-Based Nano- and Microcomposites for Implants", J. Nanotechnology, Article ID 729756 (2012).

5. S. V. Panin, L. A. Kornienko, N. Sonjaitham, L. R. Ivanova, and S. V. Shilko, Friction Wear, 33(4), 233 (2012). 